\title{
SMST 2019: Save the Date May 13-17, 2019
}

The International Conference on Shape Memory and Superelastic Technologies (SMST) will be held May 1317, 2019 at The Bodenseeforum in Konstanz, Germany. Dr. Ulrich Muerrle will serve as conference chair for the event, with Dr. Matthias Mertmann as co-chair.

SMST is the leading worldwide conference and exposition for the shape memory and superelastic technologies and is highly focused on the manufacturing and application of shape memory materials.

The preeminent experts in all aspects of working with Nitinol will also be present at this conference.

The Call for Papers is now open. The deadline to submit abstracts for consideration for SMST is October 15, 2018. To submit an abstract, visit https://www.asminternational. org/web/smst-2019/cfp.

Original, unpublished abstracts are solicited in the following topic areas:

- Shape Memory Actuators and Superelastic Damping Structures
- Shape Memory and Superelastic Medical Devices

- SMA Failure Analysis and Modeling

- Designing Next Generation Shape Memory Materials and Forms: Beyond Nitinol

- Additive Manufacturing \& Joining Technologies for Shape Memory Materials

- Material and Device Testing

- Mechanics of Shape Memory Materials: Modeling Meets Experiments

- Microstructure Characterizations of Shape Memory Materials

- Production, Processing, and Standards

- Surface Engineering and Corrosion

Interested authors should submit abstracts of 250 words or less (in English) via our online abstract service. The system is self-explanatory and will allow return access once an account has been created so abstracts can be edited as needed before the October 15, 2018 submission deadline. 